\title{
Sledging related spinal injuries and fracture patterns: a report on five cases
}

\author{
S Basu, N K Makwana, R Khazim
}

\begin{abstract}
The cases are reported of five patients who presented to The Queens Medical Centre, Nottingham after a sledging accident. All five patients presented consecutively during the first weekend in 1997 having sustained the accident in the same public park. The mechanism and subsequent fracture type is described for each. These injuries are preventable, and increasing public awareness of the risk of sledging in public places may reduce the incidence. (Br f Sports Med 1999;33:357-359)
\end{abstract}

Keywords: sledging; spine; fracture; injury

Sledging is a popular sport during the winter. Unfortunately, it is associated with a high incidence of musculoskeletal injuries. Sloan et $a l^{1}$ reported on 101 patients with various sledge related injuries seen in one accident and emergency department over an eight day period. Spinal injuries are rare but they account for a significant number of patients with long term morbidity. The factors leading to such injuries, the mechanism, and the outcome have not been previously reported. We report on five patients who sustained a spinal injury while sledging, and discuss these factors.

\section{Case reports}

Five patients, aged 15-38 years, with a spinal injury following a sledging accident were admitted to the Queens Medical Centre during the first weekend of January 1997. Of 2617 accident and emergency attenders during that week, five $(0.2 \%)$ had sustained a spinal injury. All five were sledging in the same public park. The runs used were not designated skiing areas but slopes in the park. The factors related to the injury and the mechanism of the injury were carefully recorded and later scrutinised. These were quite diverse as fig 1 shows.

The first patient hit an obstruction and was thrown up in the air with the sledge. The second patient was descending fast down a slope and landed on the path below. The third patient was sledging on a plastic sheet which turned through 180 degrees and became impaled in the snow throwing the rider off. The next patient was a young woman sitting behind her boyfriend. She fell backwards while sledging and while flat hit a series of ridges on the track. The fifth patient was sledging on an airbag and was thrown into the air after hitting an obstruction. None of the injuries were alcohol related.

All five patients sustained thoracolumbar fractures (T12-L2; fig 1) without neurological injury. The mechanism in all five was predominantly axial compression with flexion. Further imaging with computed tomography scanning was obtained in three patients to delineate the fracture pattern further. Two of these underwent surgical intervention to reduce the spinal canal compromise in one and to stabilise the spine in another.

All patients were treated by thoracolumbar orthosis and early mobilisation. All fractures united without complications, and, in the two patients who had surgery, the spinal instruments were removed electively nine months after the injury.

\section{Discussion}

Sledging is a popular recreational sport during the snow season. Prolonged snowfall in this country occurs only occasionally and usually during the month of January. It usually triggers a rush to the nearest slope with a sledge and very little planning. Not suprisingly therefore it is associated with significant injuries. ${ }^{12}$ These have ranged from acute myocardial infarction to a variety of extremity musculoskeletal injuries. Spinal injuries are rare and the factors and mechanisms responsible have not been reported. Silver ${ }^{2}$ reviewed all sledging related injuries seen in a spinal unit over a 50 year period from 1944, and found six spinal cases, five of which were sustained abroad. Sloan et $a l^{1}$ reported on 101 consecutively seen patients with a sledging injury and found five who had a spinal injury. In our study, five patients presented consecutively over one weekend having sustained these injuries in a single public park. These five patients represent a small percentage $(0.2 \%)$ of the injuries treated at the Queens Medical Centre during that week. However, five cases in seven days was a high case load for the spinal unit. In our group of patients, an obstruction on the slope was responsible for the injury in four out of the five cases. Björnstig and Tordai ${ }^{3}$ reviewed 271 patients and found an obstruction on the slope was the main cause of injury. In our study, other factors may have also contributed to these injuries, including selection of improper sledging material and sledging on steep slopes or slopes with many ridges. Sledging in areas not designated for this activity increases the
Accepted for publication 18 May 1999 
Event leading to injury
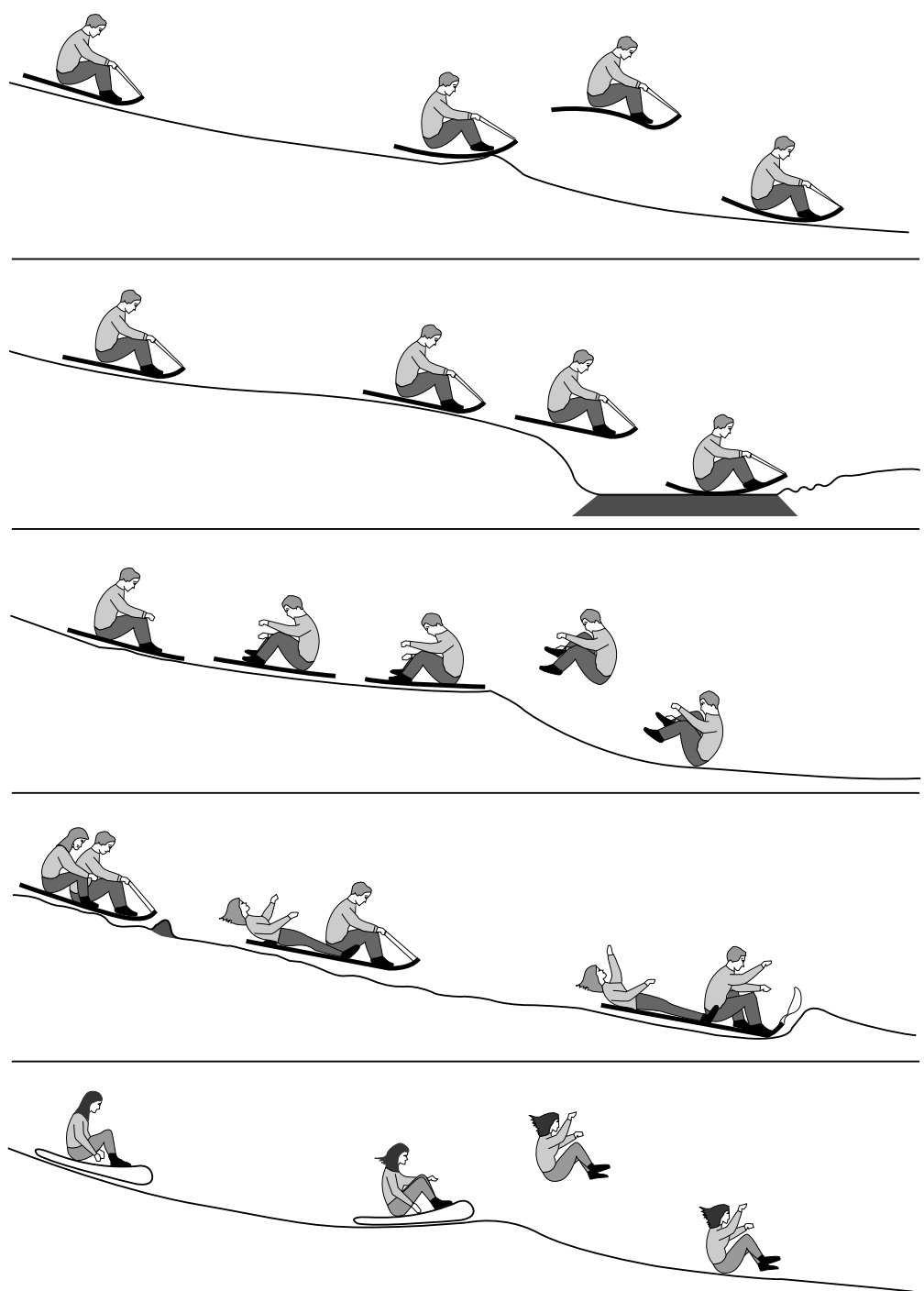

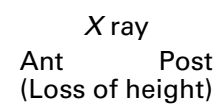

$30 \%$
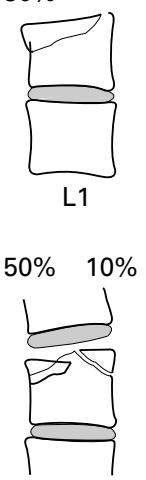

$\mathrm{T} 12$

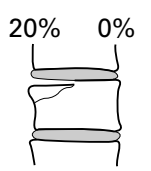

L2

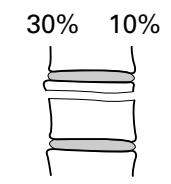

T12

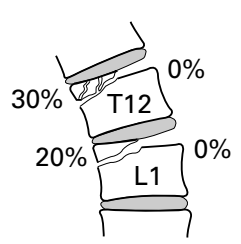

Figure 1 Schematic illustration of event and associated fracture for each case of a spinal injury suffered during a sledging accident.

chances of meeting an obstruction. It was interesting to note that, although snow was on the ground soon after Christmas in 1996, the injuries occurred three or four days later. Time and use could have made the slopes firmer and more slippery than at first, resulting in the generation of greater speeds. The high speeds achieved may have been a significant factor in the number of spinal injuries observed. Spinal injuries caused by sledging are uncommon and the mechanism of injury is poorly defined. Our study suggests that the main mechanical force is an axial compression/flexion one, predominantly involving the thoracolumbar region. They may be complicated by spinal canal compromise or instability requiring spinal surgery with instrumentation. In our study, the average hospital stay was six days. Sledging injuries have significant economic implications, and increasing public awareness and the designation of suitable slopes without obstructions may reduce the incidence.

Contributors: S B initiated the study and participated in data collection, analysis, and writing of the paper. N K M initiated the study and research and participated in data collection, analysis and writing of the paper. $\mathrm{R} \mathrm{K}$ initiated the study, developed the core issues, and participated in analysis of the data and editing of the paper.

1 Sloan JP, Maheson M, Dove AF. How dangerous is sledging? BMF 1985;290:821.

2 Silver JR. The dangers of sledging. BMF 1993;307:1602-3.

3 Björnstig U, Tordai P. Tobagganing and sledging accidents. Mechanisms and injuries. Scand $\mathcal{F}$ Soc Med 1986;14:83-6.

Take home message

Sledging can result in significant spinal injury. Increasing public awareness, sledging on designated slopes without obstructions, and the use of suitable equipment may prevent serious injury. 


\section{Commentary}

It is interesting that the study included five spinal injuries from one weekend when the previous papers by Silver and Sloan et al suggested that spinal injuries were rare. The authors suggest that the slope may have been to blame. It is my belief that the climatic changes over the last decade have resulted in lower snowfall which has affected injury rates in two ways. Firstly, as noted in the study, fewer people own appropriate sledges and more use is made of inappropriate sledging materials. Secondly, and perhaps more importantly, the lower snowfall results in inadequately covered slopes where every bump and ridge remains exposed. Inadequately covered slopes are inherently more dangerous but are eagerly sledged on by snow starved budding tobogganists.

NEIL TOWNSHEND Broadway, Worcs

\begin{tabular}{|c|c|c|}
\hline \multicolumn{3}{|c|}{ BASM Merchandise 1999} \\
\hline Ties & Single motif & $£ 6+£ 1.50 \mathrm{p} \& \mathrm{p}$ \\
\hline Blazer badge & $\begin{array}{l}\text { Wire }-4 \text { inches high } \\
\text { Wire }-3 \text { inches high }\end{array}$ & $\begin{array}{l}£ 5+£ 1.50 \mathrm{p} \& \mathrm{p} \\
£ 5+£ 1.50 \mathrm{p} \& \mathrm{p}\end{array}$ \\
\hline \multicolumn{3}{|c|}{ New stock to order } \\
\hline Sweaters & $\begin{array}{l}\text { Lambswool fine knit, V-neck or round } \\
\text { neck with small motif. Machine washable. } \\
\text { State colour and chest size required. }\end{array}$ & $£ 32+£ 3 p \& p$ \\
\hline Sweatshirts & $\begin{array}{l}\text { With small motif. } \\
\text { State colour and chest size required. }\end{array}$ & $£ 25+£^{3} \mathrm{p} \& \mathrm{p}$ \\
\hline Polo shirts & $\begin{array}{l}\text { With small motif. } \\
\text { State colour and chest size required. } \\
\text { Some education polo shirts in cream } \\
\text { and grey are also available at the same pric }\end{array}$ & $£ 23+£ 3 p \& p$ \\
\hline $\begin{array}{l}\text { Send orders t } \\
\text { Birch Lea, } 67 \\
\text { UK. (Tel: } 017\end{array}$ & $\begin{array}{l}\text { in H Clegg JP BSc LDS RCS Eng, Hon Se } \\
\text { ingfield Lane, Eccleston, St Helens, Mersey } \\
8198 \text { ) }\end{array}$ & $\begin{array}{l}\text { ecretary, } \\
\text { yside WA10 5HB, }\end{array}$ \\
\hline
\end{tabular}

